\begin{tabular}{c}
\hline Jurnal Kesehatan Masyarakat \\
http://journal.unnes.ac.id/nju/index.php/kemas
\end{tabular}

\title{
The Effect of Low and High Glycemic Load Diet on Muscle Fatigue of Young Soccer Athletes
}

\author{
Iqlima Safitri ${ }^{1 \bowtie}$, Liani Setyarsih ${ }^{1}$, Hardhono Susanto ${ }^{2}$, Suhartono ${ }^{3}$, Deny Yudi Fitranti ${ }^{1}$ \\ ${ }^{1}$ Department of Nutrition Science, Faculty of Medicine, Diponegoro University, Indonesia \\ ${ }^{2}$ Department of Medicine, Faculty of Medicine, Diponegoro University, Indonesia \\ ${ }^{3}$ Department of Public Health, Faculty of Public Health, Diponegoro University, Indonesia
}

\section{Article Info}

Article History:

Submitted February 2020

Accepted March 2020

Published July 2020

\section{Keywords:}

Glycemic Load Diet

Muscle Fatigue,

Young Soccer Athletes

DOI

https://doi.org/10.15294/

kemas.v16i1.23508

\begin{abstract}
Muscle fatigue in adolescent soccer athletes can degrade performance during a match. A low Glycemic Load (GL) diet before exercise is believed to improve soccer athlete performance because it can decrease carbohydrate oxidation during exercise and has a lower increase in lactic acid levels than a high GL diet. The study aimed to identify the effect of low and high glycemic load diets on muscle fatigue in adolescent soccer athletes. A quasi experimental with multiple series group design was conducted in November 2019 on 22 adolescent soccer athletes aged 15-17 at the Terang Bangsa Soccer School Semarang. The low GL group was given food with GL 9.15; while the high GL group contained GL 27.29. Diets given once in 2 hours before exercise. Each group was triggered by RAST (Running based Anaerobic Sprint Test) to cause anaerobic muscle fatigue. Muscle fatigue is measured using blood lactic acid, BUN (Blood Urea Nitrogen), and fatigue index. There were no significant differences in blood glucose, lactic acid, and BUN levels between the low GL and high GL groups ( $\mathrm{p}>0.05)$. Nonetheless, a low GL diet had a smaller increase in blood glucose levels $(1.91 \mathrm{mg} / \mathrm{dL}$ vs $4.09 \mathrm{mg} / \mathrm{dL})$ and lactic acid $(4.5 \mathrm{mg} / \mathrm{dL}$ vs $4.7 \mathrm{mg} /$ dL) after exercise than high BG diet. A low GL diet also has a lower fatigue index than a high GL. Keyword: glycemic load diet, muscle fatigue, lactic acid, blood urea nitrogen.
\end{abstract}

\section{Introduction}

There has been a decline in achievement on the Indonesian U-19 national soccer team. In 2013, the U-19 national team won the AFF (ASEAN Football Federation) trophy. However, in 2018 the U-19 national team failed to pass the quarter-finals at the ASIA Cup. A study by the Indonesian Football Association National Team (PSSI) showed that Indonesian professional soccer athletes often got fatigue and decreased performance especially starting in the 60th minute (Setiawan 2018). Muscle fatigue occurs when the supply of ATP (Adenosine Triphosphate) fails to meet ATP consumption during exercise. This occurs because the supply of oxygen to the cells is inadequate so that the ATP production process shifts from the aerobic process (with oxygen) to anaerobic glycolysis (without oxygen), resulting in the accumulation of lactate in the blood (Wan et al. 2017).

When the anaerobic glycolysis occured, AMP (Adenosine Monophosphat) molecules are formed to maintain the ATP/ADP (Adenosine Triphosphat/Adenosine Diphosphat) ratio. Then AMP is degraded by AMP-deaminase to IMP (Inosine Monophosphate) and ammonia. Ammonia is converted to blood urea nitrogen (BUN), so that in anaerobic conditions an increase in BUN levels will occur (Wan et al. 2017). The worse the body's adaptation to tolerate exercise, the more significantly the level of urea nitrogen increases. Therefore, BUN is another index of fatigue status besides lactic acid (Jin \& Wei 2011; Ding et al. 2011). 
A low glycemic index (GI) carbohydrate consumption mentioned more appropriate given before the endurance exercise plan than high GI foods. Low GI foods can increase blood glucose more slowly so that blood glucose becomes more stable than high GI foods (Ghiasvand et al. 2015; Cocate et al. 2011). It cause a blood glucose homeostasis, decreased carbohydrate oxidation and increased fat oxidation which can reduce lactic acid levels (Chen et al. 2008). The glycemic index of carbohydrates only describes the type of carbohydrate, without considering the total amount of carbohydrates contained in food. Meanwhile, not only the type of carbohydrate, but the amount of carbohydrate also affects postprandial glycemic and insulin responses which will have an impact on muscle glycogen supply and athlete performance (Reilly et al. 2010).

The GI concept is perfected by the glycemic load. Glycemic load (GL) is the result of the amount of carbohydrates (grams) with food GI divided by 100 . Glycemic load provides more complete information about the effect of actual food consumption on increasing blood glucose levels and can estimate the impact of a number of carbohydrates and GI on blood glucose concentration in the same time (Reilly et al. 2010).

A recent studies suggest that a low GL diet 3 hours before exercise can induce glycerol concentrations, free fatty acids, higher fatty acid oxidation and lower carbohydrate oxidation, simultaneously, during the postprandial period and during exercise (Ghiasvand et al. 2015; Chen et al. 2008). The increase in blood glucose in the low-GI low-GL (L-L) diet group occurred slowly compared to the low GI high GL (L-H) and high-GI high GL (H-H) group (Siwi et al. 2017). In addition, the increase in lactate levels after exercise was lower in the low GL (L-L and H-L) group compared to the high IG high GL (H-H) group (Chen et al. 2008). Increased fatty acid oxidation and decreased carbohydrate oxidation as a result of low carbohydrate GL intake, causing a decrease in anaerobic glycolytic activity and accumulation of blood lactic acid (Achten \& Jeukendrup 2004).

This study aims to analyze the differences in the effect of giving low and high glycemic load diets 2 hours before training on muscle fatigue of teenage soccer athletes characterized by levels of lactic acid, BUN, and fatigue index.

\section{Method}

This research is a quasi experimental pre-posttest group design with 2 treatment groups. The study was conducted at the Terang Bangsa Semarang Football School (SSB) with 11 research subjects in each group. Subjects were randomly divided into two groups consisting of low GL group and high GL group. The subjects were selected through simple random sampling. The inclusion subject criteria: (1) men aged 15-18 years, (2) joined in soccer clubs for at least 1 year, (3) a minimum of $90 \%$ physical exercise attended in the last 12 weeks, (4) not being sick, injured, or in the care of a doctor, (5) not taking carbohydrate-based supplements or sports drinks in 24 hours before the study,

Table 1. Nutritional Composition of Pre-exercise Meals

\begin{tabular}{|c|c|c|c|c|}
\hline Meal & Contents & Nutrition Analysis & $\begin{array}{l}\text { Estimated } \\
\text { mix GI }\end{array}$ & $\begin{array}{l}\text { Estimated } \\
\text { mix GL }\end{array}$ \\
\hline $\begin{array}{l}\text { Low GL } \\
\text { (Low GI Low } \\
\text { GL/L-L) }\end{array}$ & $\begin{array}{l}\text { Boiled spaghetti }(90 \mathrm{~g}) \\
\text { Scramble egg }(50 \mathrm{~g}) \\
\text { Cornet beef }(25 \mathrm{~g}) \\
\text { Palm oil }(10 \mathrm{~g})\end{array}$ & $\begin{array}{l}400.18 \mathrm{kkal} \\
28.77 \mathrm{~g} \text { CHO }(30 \%) \\
20.66 \mathrm{~g} \text { fat }(46 \%) \\
23.56 \mathrm{~g} \text { protein }(24 \%)\end{array}$ & 31.79 & 9.15 \\
\hline $\begin{array}{l}\text { High GL } \\
\text { (Medium GI High } \\
\text { GL/M-H) }\end{array}$ & $\begin{array}{l}\text { Boiled corn }(100 \mathrm{~g}) \\
\text { Sweetened condensed milk } \\
(40 \mathrm{~g}) \\
\text { Cheddar kraft cheese }(20 \\
\mathrm{g}) \\
\text { Butter }(10 \mathrm{~g})\end{array}$ & $\begin{array}{l}391.53 \mathrm{kkal} \\
45.586 \mathrm{~g} \mathrm{CHO}(47 \%) \\
19.47 \mathrm{~g} \text { fat }(45 \%) \\
9.09 \mathrm{~g} \text { protein }(8 \%)\end{array}$ & 59.86 & 27.29 \\
\hline
\end{tabular}


(6) not doing high intensity physical exercise in 24 hours before the study, (7) not smoking and consuming alcohol.

The low GL group was given carbohydrate-source foods with a glycemic load of 9.15, while the high GL group was given carbohydrate-source foods with a glycemic load of 27.29 (Table 1). Food is given once at 2 hours before training. Subjects were fasted 10 hours before the intervention.

The data collection includes the subject's characteristics which are name, age, and date of birth taken using questionnaires. Weight, height, body fat percent, and muscle mass percent data were measured before giving intervention using the Bioelectric Impedance Analyzer (BIA). Data on physical activity and sleep duration of the last 24 hours were measured using the Physical Activity Level (PAL) form. Data of the last 24-hour meal intake was measured using a 24-hour recall form. VO2max data was measured using a bleep test.

Blood glucose levels were measured using a glucometer and blood lactic acid levels with Accutrend Plus Brand Roche. Hemoglobin levels were measured using cyanthemoglobin method. BUN levels were measured using the colorimetric method with a photometer or chemical analyzer. Blood glucose, lactic acid, and BUN levels were measured 3 times, those are before the intervention, immediately after the RAST exercise test, and 1 hour after exercise. The fatigue index is measured using the RAST (The Running based Anaerobic Sprint Test) method. Subjects asked to run sprints on a 35-meter straight track with a maximum speed of six times with a 10 -second pause between each repetition. The fatigue index is calculated by the formula (maximum power output minimum power output $) \div$ total time for six sprints.

The data of fatigue index, lactic acid and BUN levels before intervention, immediately after exercise, 1 hour after exercise (recovery period), and subject characteristics between the two groups were examined using the independent-t-test and Mann-Whitney test. Multivariate tests were performed if there were different in subject characteristics data between the two groups using General Linier Model (GLM) repeatedly measures.

\section{Result and Discussion}

The study was conducted on 22 adolescent soccer athletes with an average age of 16 years. Data on the subject's characteristics showed no significant differences in age, Body Mass Index (BMI), fat mass percent, VO2max, hydration status, hemoglobin levels, physical activity, and sleep duration between the two groups $(p>0.05)$ (Table 2). Only a percent of muscle mass showed a difference between

Table 2. Subject Characteristics and Consumption Level of Nutrient Intake in Both Groups

\begin{tabular}{|c|c|c|c|c|c|c|c|}
\hline \multirow{2}{*}{ Variable } & \multicolumn{3}{|c|}{ Low GL $(\mathrm{n}=11)$} & \multicolumn{3}{|c|}{ High GL $(\mathrm{n}=11)$} & \\
\hline & Mean \pm SD & Min & Max & Mean \pm SD & Min & Max & \\
\hline Age (years) & $16 \pm 0.77$ & 15 & 17 & $15.91 \pm 0.83$ & 15 & 17 & $0.78 \mathrm{~b}$ \\
\hline BMI (kg/m2) & $21.02 \pm 1.64$ & 18.40 & 23.50 & $22.84 \pm 2.49$ & 19.10 & 26.30 & $0.06 \mathrm{a}$ \\
\hline Fat mass percent (\%) & $15.96 \pm 2.53$ & 12.00 & 19.60 & $18.31 \pm 3.56$ & 13.90 & 23.10 & $0.09 \mathrm{a}$ \\
\hline Muscle mass percent (\%) & $41.92 \pm 1.93$ & 39.10 & 44.50 & $39.91 \pm 2.25$ & 37.50 & 43.10 & $0.03 \mathrm{a}$ \\
\hline VO2max (ml/kg/minutes) & $48.93 \pm 3.58$ & 44.65 & 57.46 & $45.78 \pm 4.84$ & 37.10 & 54.10 & $0.10 \mathrm{a}$ \\
\hline Hydration status (score) & $3.64 \pm 1.8$ & 1 & 6 & $3.18 \pm 2.36$ & 1 & 7 & $0.46 \mathrm{~b}$ \\
\hline Hemoglobin level (g/dl) & $15.44 \pm 0.99$ & 13.8 & 17.3 & $14.82 \pm 0.85$ & 13.4 & 16.4 & $0.13 \mathrm{a}$ \\
\hline Physical Activity (kkal/hour) & $1.54 \pm 0.25$ & 1.24 & 1.88 & $1.53 \pm 0.25$ & 1.13 & 1.88 & $0.85 \mathrm{a}$ \\
\hline Sleep duration (hour) & $8.61 \pm 1.17$ & 7 & 10 & $8.12 \pm 1.27$ & 7 & 11 & $0.26 \mathrm{~b}$ \\
\hline Energy intake (\%) & $75.78 \pm 23.93$ & 44.92 & 116.67 & $75.19 \pm 21.78$ & 41.63 & 116.82 & $0.95 \mathrm{a}$ \\
\hline Carbohydrate intake (\%) & $67.27 \pm 20.78$ & 36.38 & 106.79 & $62.91 \pm 16.69$ & 31.43 & 91.07 & $0.59 \mathrm{a}$ \\
\hline Fat intake (\%) & $96.37 \pm 33.74$ & 48.69 & 153.41 & $98.97 \pm 24.37$ & 65.01 & 132.92 & $0.86 \mathrm{a}$ \\
\hline Protein intake (\%) & $73.93 \pm 28.55$ & 32.99 & 133.58 & $73.85 \pm 22.73$ & 40.08 & 120.41 & $0.99 \mathrm{a}$ \\
\hline
\end{tabular}

${ }^{a}$ Independent $t$-test, ${ }^{b}$ Mann-Whitney,

Soure: Primary data 
the two groups $(\mathrm{p}<0.05)$. However, the mean VO2max, hydration status, hemoglobin level, and sleep duration in the low BG group were higher than the high of BG group.

Consumption levels of energy, carbohydrate, fat, and protein intake showed no significant difference between the two groups $(p>0.05)$ (Table 2). Both of groups have low consumption levels of energy, carbohydrate, and protein intake $(<80 \%)$ (Setiawan 2018). Even so, the mean of carbohydrate intake consumption level was higher in the low BG group than the high BG.

The consumption level of carbohydrate intake for endurance athletes is highly important to prevent athletes from muscle fatigue. Carbohydrate-rich diets are recommended for endurance exercise because they are associated with increased muscle glycogen stores, liver glycogen concentrations, and delayed onset of fatigue (Peinado et al. 2013). Low consumption levels of carbohydrate intake in both groups led to a lack of muscle and liver glycogen stores. This can reduce the rate of ATP regeneration and $\mathrm{Ca}^{2+}$ release in the sarcoplasmic reticulum (RS) during exercise (Ørtenblad et al. 2013). As a result the muscles are unable to maintain an adequate supply of energy for contraction and provide strength so that fatigue occurs
(Ørtenblad et al. 2013; Wan et al. 2017)and the importance of muscle glycogen on performance has subsequently been confirmed in numerous studies. However, the link between glycogen depletion and impaired muscle function during fatigue is not well understood and a direct cause-and-effect relationship between glycogen and muscle function remains to be established. The use of electron microscopy has revealed that glycogen is not homogeneously distributed in skeletal muscle fibres, but rather localized in distinct pools. Furthermore, each glycogen granule has its own metabolic machinery with glycolytic enzymes and regulating proteins. One pool of such glycogenolytic complexes is localized within the myofibrils in close contact with key proteins involved in the excitationcontraction coupling and $\mathrm{Ca} 2+$ release from the sarcoplasmic reticulum (SR).

There is no significant difference in blood glucose levels at all three times between the two groups ( $>0.05$ ) (Table 3 ). This finding is similar to previous studies which showed no difference in blood glucose levels immediately after running 2400 meters between the $\mathrm{L}-\mathrm{L}$ group (low GI low GL) and L-H (low GI high GL) (Siwi et al. 2017). This possible occurred because in this study, the carbohydrate content in the low BG group was too low at only $30 \%$

Table 3. Blood Glucose, Lactic Acid, BUN Levels, and Fatigue Index in Low and High BG Groups according to Three Times

\begin{tabular}{llll}
\hline \multirow{2}{*}{ Variable } & \multicolumn{2}{l}{ Type of Diet } & $\mathrm{p}$ \\
\cline { 2 - 3 } Blood Glucose & Low GL & High GL & \\
Before intervention & & & $0.32 \mathrm{a}$ \\
Immediately after exercise & $95.09 \pm 15.93$ & $89.55 \pm 8.42$ & $0.52 \mathrm{a}$ \\
Recovery period & $97 \pm 14.18$ & $93.64 \pm 9.55$ & $0.85 \mathrm{a}$ \\
Lactic Acid & $87.55 \pm 6.23$ & $87.00 \pm 6.96$ & \\
Before intervention & & & $0.14 \mathrm{a}$ \\
Immediately after exercise & $2.10 \pm 0.55$ & $2.41 \pm 0.37$ & $0.69 \mathrm{a}$ \\
Recovery period & $6.64 \pm 2.02$ & $7.11 \pm 3.24$ & $0.19 \mathrm{~b}$ \\
BUN & $2.14 \pm 1.00$ & $2.71 \pm 1.21$ & \\
Before intervention & & & $0.56 \mathrm{a}$ \\
Immediately after exercise & $10.79 \pm 1.41$ & $11.26 \pm 2.26$ & $0.47 \mathrm{~b}$ \\
Recovery period & $11.59 \pm 1.54$ & $11.30 \pm 1.76$ & $0.79 \mathrm{~b}$ \\
Fatigue Index & $11.45 \pm 1.75$ & $11.37 \pm 1.77$ & $0,32 \mathrm{a}$ \\
\hline
\end{tabular}

${ }^{a}$ Independent $t$-test, ${ }^{b}$ Mann-Whitney

Soure: Primary data 
(Table 1). Previous studies have suggested low GI foods that are rich in carbohydrate content $(1.5 \mathrm{~g} / \mathrm{kg} \mathrm{BW})$ which can help to maintain muscle glycogen and provide fuel for sprint runs with high intensity (Little et al. 2010). Other studies have shown that consuming lowGI low-GL (L-L) foods with a high carbohydrate content of $66 \%$ can reduce carbohydrate oxidation and provide blood glucose during exercise (Chen et al. 2008), separated by at least 7 days. Carbohydrate (CHO. Too low carbohydrate content in the low GL group, can lead to increased carbohydrate oxidation and earlier remove muscle glycogen stores during RAST than the high GL group. On the other hand, carbohydrate content in the high GL group was higher than the low GL which was $47 \%$ with moderate IG (59.86). It is possible that the desired effect tends to occur in the high GL group.

Similar to blood glucose levels, lactic acid and BUN levels at all three times also showed no significant difference between the two groups $(p>0.05)$ (Table 3). This finding differs from previous studies which showed differences in lactic acid levels between the L-L group (low GI low GL) with H-H (high GI high GL) and H-L (high GI low GL) during and after a $10 \mathrm{~km}$ run test (Chen et al. 2008), separated by at least 7 days. Carbohydrate (CHO. However, the increase in post-exercise lactic acid levels was lower in the low BG group compared to the high BG group (Figure 2).

The RAST test is high intensity exercise (> 85\% VO2max) with short duration about 90 120 seconds. This exercise requires glucose as the main energy-producing substrate until the third minute of exercise (Peinado et al. 2013). This exercise will lead to anaerobic glycolysis process to provide ATP in a fast time which produces lactic acid as a residue. Anaerobic glycolysis uses glucose stores which are mostly derived from muscle glycogen and blood glucose to produce ATP (Susilo \& Mardiana 2018). Glycogen in skeletal muscle is extremely important to provide a fast ATP mechanism in muscle cells (Ørtenblad et al. 2013), and the importance of muscle glycogen on performance has subsequently been confirmed in numerous studies. However, the link between glycogen depletion and impaired muscle function during fatigue is not well understood and a direct cause-and-effect relationship between glycogen and muscle function remains to be established. The use of electron microscopy has revealed that glycogen is not homogeneously distributed in skeletal muscle fibres, but rather localized in distinct pools. Furthermore, each glycogen granule has its own metabolic machinery with glycolytic enzymes and regulating proteins. One pool of such glycogenolytic complexes is localized within the myofibrils in close contact with key proteins involved in the excitationcontraction coupling and $\mathrm{Ca} 2+$ release from the sarcoplasmic reticulum (SR.

The absence of differences in the levels of lactic acid and BUN between the two groups is possible due to the low level of consumption of carbohydrate intake before intervention in the two groups resulting in a lack of muscle and liver glycogen stores in both groups (Ørtenblad et al. 2013), and the importance of muscle glycogen on performance has subsequently been confirmed in numerous studies. However, the link between glycogen depletion and impaired muscle function during fatigue is not well understood and a direct cause-andeffect relationship between glycogen and muscle function remains to be established. The use of electron microscopy has revealed that glycogen is not homogeneously distributed in skeletal muscle fibres, but rather localized in distinct pools. Furthermore, each glycogen granule has its own metabolic machinery with glycolytic enzymes and regulating proteins. One pool of such glycogenolytic complexes is localized within the myofibrils in close contact with key proteins involved in the excitationcontraction coupling and $\mathrm{Ca} 2+$ release from the sarcoplasmic reticulum (SR). Lack of glucose from glycogen stores and exogenous intake in the interventions in both groups led to gluconeogenesis. During anaerobic conditions, lactate is the main precursor of gluconeogenesis. Gluconeogenesis from lactate is the main production of glucose in the liver and kidneys (Glenn et al. 2015). Lactate is converted into pyruvate by lactate dehydrogenase (LDH) and then produces glucose-6-phosphate and it becomes glucose (Weinstein et al. 2006; Emhoff et al. 2013)the liver is not enlarged in GSD0. Patients with GSD0 typically have fasting ketotic 
hypoglycemia without prominent muscle symptoms. Most children are cognitively and developmentally normal. Short stature and osteopenia are common features, but other long-term complications, common in other types of GSD, have not been reported in GSD0. Until recently, the definitive diagnosis of GSD0 depended on the demonstration of decreased hepatic glycogen on a liver biopsy. The need for an invasive procedure may be one reason that this condition has been infrequently diagnosed. Mutation analysis of the GYS2 gene (12p12.2.
The higher levels of lactic acid reflect the higher gluconeogenesis (Emhoff et al. 2013). The level of consumption of carbohydrate intake is equally low in both groups allowing an increase in gluconeogenesis during RAST at the same level which is marked by increasing levels of lactic acid after RAST almost the same in both groups (Table 3 ).

Although there is no difference between the two groups at all three times, the increase of blood glucose from before the intervention to immediately after exercise was twice lower in

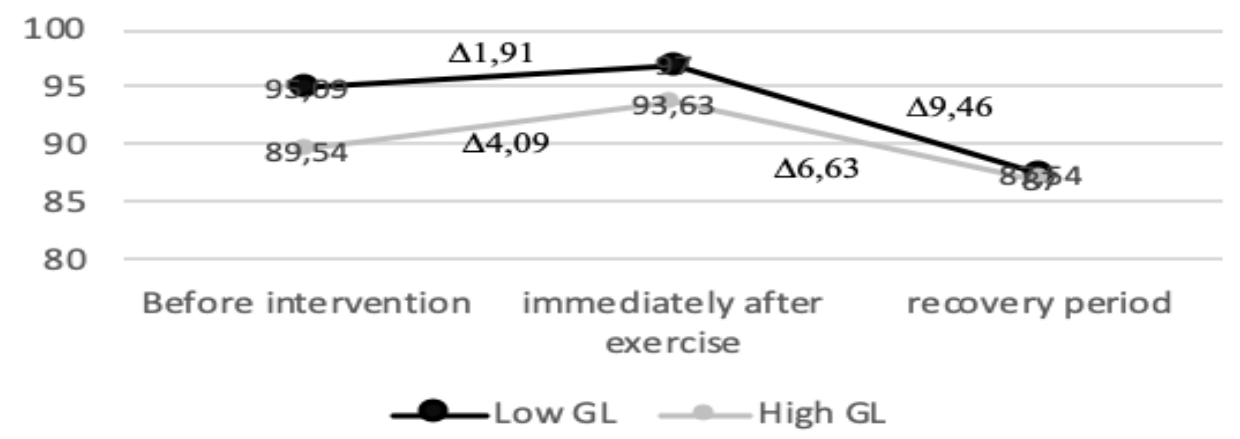

Figure 1. Graph of Changes in Blood Glucose Levels in Low GL and High GL Group According to Three Times

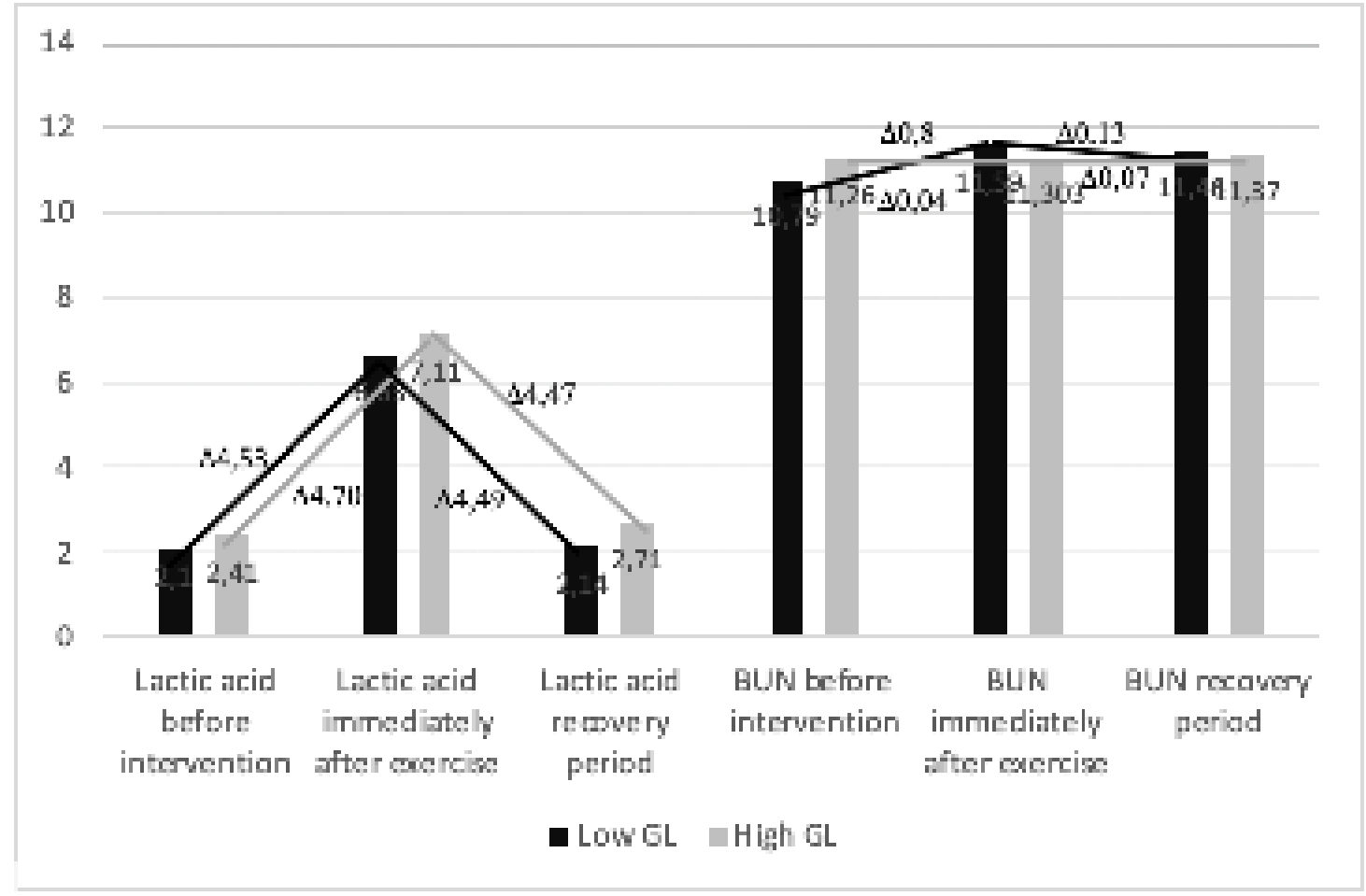

Figure 2. Graph of Changes in Lactic Acid and BUN Levels in low GL and high GL Group According to Three Times 
the low GL group than the high GL (Figure 1). Lactic acid levels at all three times also showed lower levels in the low GL group (Figure 2). This incident is due to higher protein content (24\%) and low glycemic index in the low GL group than the high GL group. The recent study showed that diets high protein with low glycemic index carbohydrates can reduce postprandial hyperglycemia and lactic academia. This diet can increase gluconeogenesis because it provides more major gluconeogenic precursors namely alanine which can be used for endogenous glucose production (Weinstein et al. 2006)the liver is not enlarged in GSD0. Patients with GSD0 typically have fasting ketotic hypoglycemia without prominent muscle symptoms. Most children are cognitively and developmentally normal. Short stature and osteopenia are common features, but other long-term complications, common in other types of GSD, have not been reported in GSD0. Until recently, the definitive diagnosis of GSD0 depended on the demonstration of decreased hepatic glycogen on a liver biopsy. The need for an invasive procedure may be one reason that this condition has been infrequently diagnosed. Mutation analysis of the GYS2 gene (12p12.2. Alanine will be converted into pyruvate by alanine aminotransferase then produce glucose6-phosphate and become glucose (Weinstein et al. 2006; Emhoff et al. 2013)the liver is not enlarged in GSD0. Patients with GSD0 typically have fasting ketotic hypoglycemia without prominent muscle symptoms. Most children are cognitively and developmentally normal. Short stature and osteopenia are common features, but other long-term complications, common in other types of GSD, have not been reported in GSD0. Until recently, the definitive diagnosis of GSD0 depended on the demonstration of decreased hepatic glycogen on a liver biopsy. The need for an invasive procedure may be one reason that this condition has been infrequently diagnosed. Mutation analysis of the GYS2 gene (12p12.2.)

An interesting point is found on the graph of changes in BUN levels in the three times between the two groups. The dynamics of changes in BUN levels was occurred in the low BG group which is an increase BUN levels at immediately after RAST and then a decrease BUN levels during the recovery period. However, this did not occur in the high BG group. BUN levels in the three times are not much different and tend to rise despite the very small increase (Figure 2). This occurs probably because of the high protein content in the diet of low GL group which reaches $24 \%$. Meanwhile, the high BG group only contained $8 \%$ protein. The high protein content in the low BG group makes the body increase the oxidation of amino acids that produce urea and ammonia (Probosari 2019). Urea that binds to nitrogen circulates in the blood in the form of blood urea nitrogen (BUN) wherein urea will release excess nitrogen through the kidneys. Urea is used as a marker of protein catabolism. The higher the protein intake, the higher the urea production (Schutz 2011).

The high increase in BUN levels after RAST in the low BG group reflects an increase in the use of protein as an energy substrate during RAST (Palacios et al. 2015). The low carbohydrate content $(30 \%)$ and high protein content (24\%) in the low BG diet results in a lack of glucose availability as an ATP-producing energy substrate resulting in gluconeogenesis with protein substrates. While in the high BG group the carbohydrate content (47\%) was still sufficient to meet the energy substrate during the RAST so that the utilization of protein as energy did not occur in the high BG group.

Fatigue Index after RAST showed no significant difference between the two groups ( $p>0.05$ ) (Table 3). This is in line with previous studies which showed no difference in travel time completing a $10 \mathrm{~km}$ run between the L-L group (low GI low GL) with H-H (high GI high BG) and H-L (high GI low GL), although there were differences in metabolic responses between all three groups (Chen et al. 2008) separated by at least 7 days. Carbohydrate (CHO. However, the fatigue index were lower in the low GL group compared to the high GL group. The difference in mean percent of muscle mass between the low GL and high GL groups ( $p<0.05)$ could be the cause of this occurs. Percent of muscle mass in the low GL group was higher than the high GL group.

The amount of muscle mass affects the total amount of creatine in the body (Brosnan et al. 2011). Creatine (Cr) is a type of amino acid 
Table 4. Effect of Glycemic Load Diets on Muscle Fatigue After Being Controlled by Muscle Mass Percentages

\begin{tabular}{lll}
\hline \multirow{2}{*}{ Variable } & Muscle Fatigue & \\
\cline { 2 - 3 } & Lactic Acid (p) & BUN $(\mathrm{p})$ \\
\hline Muscle mass percent & $0,825^{\mathrm{a}}$ & $0,691^{\mathrm{a}}$ \\
\hline Glycemic load diet & $0,464^{\mathrm{a}}$ & $0,827^{\mathrm{a}}$ \\
\hline
\end{tabular}

ageneral linear model (GLM) repeated measures

Soure: Primary data

that is stored in the muscles as an energy source (Susilo \& Mardiana 2018). The anaerobic energy system at RAST, $72 \%$ is very dependent in $\mathrm{PCr}$ (phosphocreatine) in skeletal muscle (Kim et al. 2011). PCr is broken down into inorganic phosphate (phosphate inorganic/PI) and creatine by creatine-phosphokinase. PI binds to adenosine diphosphate (ADP) molecules to rebuild adenosine triphosphate (ATP) (Feher 2017). The phosphagen system and creatine phosphate are needed in sprints such as RAST to produce instant energy (Surwase SP, Deore, Deepmala N, Pallod KG 2015). The low GL group had a higher muscle mass percentage (41.92\%) than the high GL group (39.91\%). This is beneficial for the low GL group because they have higher creatine phosphate deposits than the high GL group. As a result the low GL group can form higher instant energy and have a lower fatigue index than the high BG group.

Although the mean of muscle mass percent between the two groups showed significant differences, the results of multivariate tests showed that the percent of muscle mass when compared with a glycemic load diet did not have an influence on lactic acid levels and BUN ( $>$ 0.05) (Table 5).

The absence of data on muscle glycogen concentration prior to exercise became a limitation in this study because it could not be determined whether there was no difference in physiological responses between the two intervention groups due to pre-existing basal muscle glycogen content or by dietary interventions during the research. Moreover the absence of a standard glycemic index of a food is still debated in this issue. The glycemic index varies and is greatly influenced by many factors including processing, processing time, portion size, geographical area where food grows, and varieties. This causes the estimated glycemic load obtained from IG x carbohydrates to be uncertain for all meals in all portion sizes (Chen et al. 2008)separated by at least 7 days. Carbohydrate (CHO. Therefore, it is necessary to test the glycemic index of mixed foods on each diet before be given to athletes.

The type of exercise influences the appropriate type of diet. The RAST is high intensity exercise (> 85\% VO2max) with a short duration of 90-120 seconds. This exercise requires glucose as the main energy-producing substrate until the 3rd minute of exercise (Peinado et al. 2013). Therefore, it is very important to present a high-carbohydrate-lowGI diet to provide exogenous carbohydrates to maintain blood glucose levels during the RAST. A low GI low GL diet with a composition of $66 \%$ carbohydrate, $24 \%$ fat, and $15 \%$ protein can be a good choice of diet before high intensity short duration exercise. This diet is believed to have a good metabolic response to maintain blood glucose stability and prevents the buildup of lactic acid (Chen et al. 2008), separated by at least 7 days. Carbohydrate (CHO. Fruits and vegetables high in fiber, whole-grain cereals, and legumes such as kidney beans, black beans, and peas are a combination of foods that can meet the above diet (Beavers \& Leutholtz 2008).

\section{Conclusion}

Administering a low GL diet 2 hours before RAST compared with a high GL diet did not significantly correlate with muscle fatigue signed by no difference in levels of lactic acid, BUN, and fatigue index between the two groups. However increased blood glucose and lactic acid levels post RAST is smaller in low GL group than high GL group. The right type of diet for high intensity short duration exercises such as RAST is a low GI low GL diet with a composition $66 \%$ carbohydrate, $24 \%$ fat, and $16 \%$ protein. 


\section{References}

Achten, J., \& Jeukendrup, A.E., 2004. Relation Between Plasma Lactate Concentration and Fat Oxidation Rates Over A Wide Range of Exercise Intensities. International Journal of Sports Medicine, 25(1), pp.32-7.

Beavers, K.M., \& Leutholtz, B., 2008. Glycemic Load Food Guide Pyramid for Athletic Performance. National Strength and Conditioning Association, 30(3), pp.10-14.

Brosnan, J.T., da Silva, R.P., \& Brosnan, M.E., 2011. The Metabolic Burden of Creatine Synthesis. Amino acids, 40(5), pp.1325-31.

Chen, Y.J., Wong, S.H., Wong, C.K., Lam, C.W., Huang, Y.J., \& Siu, P.M., 2008. Effect of Preexercise Meals with Different Glycemic Indices and Loads on Metabolic Responses and Endurance Running. International journal of sport nutrition and exercise metabolism, 18(3), pp.281-300.

Cocate, P.G., Pereira, L.G., Marins, J.C.B., Cecon, P.R., Bressan, J., \& Alfenas, R.C.G., 2011. Metabolic Responses To High Glycemic Index and Low Glycemic Index Meals: A Controlled Crossover Clinical Trial. Nutrition Journal, 10(1), pp.1-10.

Ding, J.F., Li, Y.Y., Xu, J.J., Su, X.R., Gao, X., \& Yue, F.P., 2011. Study on Effect of Jellyfish Collagen Hydrolysate on Anti-Fatigue and Anti-Oxidation. Food Hydrocolloids, 25(5), pp.1350-3.

Emhoff, C.A.W., Messonnier, L.A., Horning, M.A., Fattor, J.A., Carlson, T.J., \& Brooks, G.A., 2013. Gluconeogenesis and Hepatic Glycogenolysis During Exercise at The Lactate Threshold. Journal of Applied Physiology, 114(3), pp.297-306.

Feher, J., 2017. Muscle Energetics, Fatigue, and Training. Quantitative Human Physiology, Elsevier.

Ghiasvand, R., Sharifhosein, Z., Esmailzadeh, A., \& Feizi, A., 2015. Comparison Between Preexercise Meals Intake Effect with Different Glycemic Load on Exercise Performance in Female Athletes. Journal of Food and Nutrition Research, 3(2), pp.88-93.

Glenn, T.C., Martin, N.A., McArthur, D.L., Hovda, D.A., Vespa, P., Johnson, M.L., Horning, M.A., \& Brooks, G.A., 2015. Endogenous Nutritive Support after Traumatic Brain Injury: Peripheral Lactate Production for Glucose Supply via Gluconeogenesis. Journal of Neurotrauma, 32(11), pp.811-819.

Jin, H.M., \& Wei, P., 2011. Anti-Fatigue Properties of Tartary Buckwheat Extracts in Mice. International Journal of Molecular Sciences,
12(8), pp.4770-80.

Kim, J., Cho, H.C., Jung, H.S., \& Yoon, J.D., 2011. Influence of Performance Level on Anaerobic Power and Body Composition In Elite Male Judoists. Journal of Strength and Conditioning Research, 25(5), pp.1346-54.

Little, J.P., Chilibeck, P.D., Ciona, D., Forbes, S., Rees, H., Vandenberg, A., \& Zello, G.A., 2010. Effect of Low- and High-Glycemic-Index Meals on Metabolism and Performance during High-Intensity, Intermittent Exercise. International Journal of Sport Nutrition and Exercise Metabolism, 20, pp.447-56.

Ørtenblad, N., Westerblad, H., \& Nielsen, J., 2013. Muscle Glycogen Stores and Fatigue. Journal of Physiology, 591(18), pp.4405-13.

Palacios, G., Chamizo, R.P., Palacios, N., MarotoSánchez, B., Aznar, S., \& González-Gross, M., 2015. Biomarkers of Physical Activity and Exercise. Nutricion hospitalaria, 31(Supl.3), pp.237-44.

Peinado, A.B., Rojo-Tirado, M.A., \& Benito, P.J., 2013. Sugar and Physical Exercise; The Importance of Sugar for Athletes. Nutricion Hospitalaria, 28(4), pp.48-56.

Probosari, E., 2019. Effect of Diet Protein on the Glycemic Index. Journal of Nutrition and Health, 7(1), pp.33-9.

Reilly, J.O., Wong, S.H.S., \& Chen, Y., 2010. Glycaemic Index , Glycaemic Load and Exercise Performance. Sport Medicine, 40(1), pp.27-39.

Rimbawan., \& Siagian, A., 2004. The Glycemic Index of Food is an Easy Way to Choose Healthy Foods I., Jakarta: Penebar Swadaya.

Schutz, Y., 2011. Protein Turnover, Ureagenesis and Gluconeogenesis. International Journal for Vitamin and Nutrition Research, 81(2), pp.101-7.

Setiawan, M.I., 2018. Effect of Milk Protein Supplementation on Muscle Performance and Total Antioxidant Status in Soccer Athletes. Thesis. Semarang: University of Diponegoro.

Siwi, T.P., Dieny, F.F., \& Fitranti, D.Y., 2017. Effect of Diet by Regulating Glycemic Index and Glycemic Load on Blood Glucose Levels of Teenage Football Athletes. Journal of Indonesian Nutrition, 6(1), pp.1-8.

Surwase, S.P., Deore, D.N., Pallod, K.G.K.S., 2015. Comparative Study of Aerobic and Anaerobic Power in Football Payers and Control Group. IOSR Journal of Dental and Medical Sciences, 14(5), pp.53-6.

Susilo, M.T. \& Mardiana, M., 2018. The Palm Date Treatment To Anaerobic Muscle Fatigue on 
Iqlima Safitri, et al / The Effect of Low and High Glycemic Load Diet on Muscle Fatigue of Young Soccer Athletes

Running Athlete. In The 4th International Seminar on Public Health Education. pp. 128-31.

Wan, J., Qin, Z., Wang, P., Sun, Y., \& Liu, X., 2017. Muscle Fatigue: General Understanding and Treatment. Experimental and Molecular Medicine, 49(10), pp.e384-11.
Weinstein, D.A., Catherine, E., Correia, B.S., Andrew, C., Saunders, B.S., Joseph, I., Wolfsdorf, M.B., 2006. Hepatic Glycogen Synthase Deficiency: an Infrequently Recognized Cause Of Ketotic Hypoglycemia. Molecular Genetics and Metabolism, 87(4), pp.284-288. 